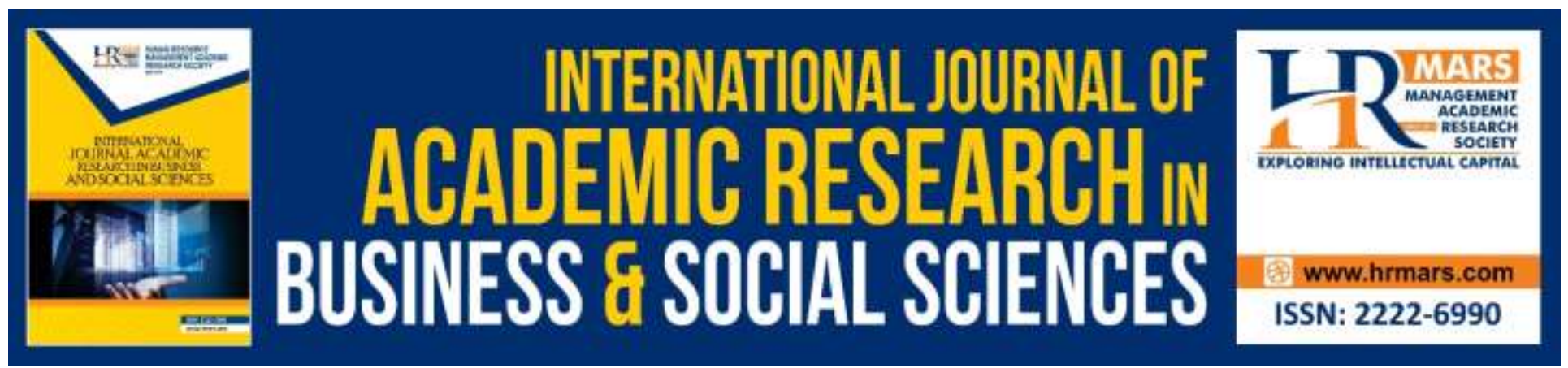

\title{
Perception of Team Based Learning on Medical and Health Terminology Course
}

\author{
Nor Azmaniza Azizam, Siti Noorsuriani Maon, Mohd Redhuan Dzulkipli, Nor \\ Intan Shamimi Abdul Aziz
}

To Link this Article: http://dx.doi.org/10.6007/IJARBSS/v9-i13/6243

DOI: 10.6007/IJARBSS/v9-i13/6243

Received: 26 March 2019, Revised: 27 May 2019, Accepted: 26 July 2019

Published Online: 24 August 2019

In-Text Citation: (Azizam, Maon, Dzulkipli, \& Aziz, 2019)

To Cite this Article: Azizam, N. A., Maon, S. N., Dzulkipli, M. R., \& Aziz, N. I. S. A. (2019). Perception of Team Based Learning on Medical and Health Terminology Course. International Journal of Academic Research in Business and Social Sciences, 9(13), 67-76.

Copyright: (C) 2019 The Author(s)

Published by Human Resource Management Academic Research Society (www.hrmars.com)

This article is published under the Creative Commons Attribution (CC BY 4.0) license. Anyone may reproduce, distribute, translate and create derivative works of this article (for both commercial and non-commercial purposes), subject to full attribution to the original publication and authors. The full terms of this license may be seen

at: http://creativecommons.org/licences/by/4.0/legalcode

Special Issue: Revolutionizing Education: Challenges, Innovation, Collaboration, 2019, Pg. 67- 76 http://hrmars.com/index.php/pages/detail/IJARBSS

JOURNAL HOMEPAGE

Full Terms \& Conditions of access and use can be found at http://hrmars.com/index.php/pages/detail/publication-ethics 


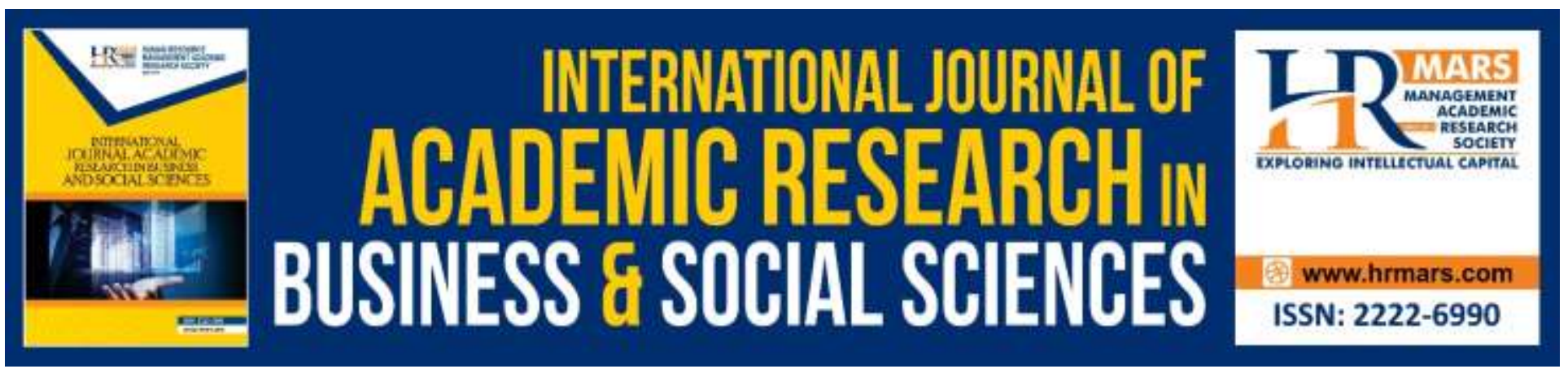

\title{
Perception of Team Based Learning on Medical and Health Terminology Course
}

\author{
Nor Azmaniza Azizam, Siti Noorsuriani Maon, Mohd Redhuan \\ Dzulkipli, Nor Intan Shamimi Abdul Aziz
}

Faculty of Business and Management, Universiti Teknologi MARA, UiTM Puncak Alam Campus, 42300 Puncak Alam, Selangor, Malaysia

Email: norazm@puncakalam.uitm.edu.my

\begin{abstract}
Team-based learning (TBL) is a teaching approach that has been designed to provide students with both conceptual and applied knowledge. TBL has been widely implemented in healthcare education, yet, very little information about the implementation of TBL in Universiti Teknologi MARA, and this is the first study conducted that uses TBL intervention for Health and Administration program particularly for the medical and health terminology subject. A pre and post study was designed to evaluate student's perception towards TBL and team work before and after TBL implementation as well as to measure the knowledge of TBL among lecturers in the Faculty of Business and Management, Universiti Teknologi MARA Selangor, Puncak Alam Campus. TBL was conducted in two phases; which begin with an Individual Readiness Test (IRT) followed by the Group Readiness Test (GRT). A total of 33 students participated in this study. The data was collected in July 2018, using 27-items self-administered questionnaire. Perception of TBL was measured by twelve (12) items, while, teamwork was assesed by eight (8) items and facilitator's knowledge was evaluated by seven (7) items. Results show that students rated positive evaluation towards TBL and teamwork. Also, there was significant difference in mean score of perception before and after implementation of $T B L, P<0.05$. Meanwhile, the knowledge of $T B L$ among facilitators were fairly considered as good and poor. Implementation of TBL in higher education is especially relevant as it motivates aspect-independent skills such as communication, leadership and problem solving. Hence, this study provides meaningful information to the higher management by taking into account of the student's experiences in learning to improve teaching strategy in future. Also, it will help in the successful implementation of TBL in various courses and programs in Universiti Teknologi MARA.
\end{abstract}

Keywords: Team-Based Learning, Medical and Health Terminology, Universiti Teknologi MARA 


\section{Introduction}

Nowadays, medical education pedagogy has evolved to suit with the current needs of the academic world to further enhance the students experience and understanding in the course students are taking. The evolution is in line with the rapid advancement of the technology as one of the tools to assist the learning process especially in the medical teaching which emphasize robust and the zerorated hands on techniques amongst its medical fraternity.

\section{Literature Review}

Team based learning (TBL) is defined as pedagogical method that intend to transform the traditional learning method to an interactive and problem solving skills among the respective course learner especially in medical (Hassan, Ibrahim, \& Hassan, 2018). As compared to the traditional lecture based learning ( $L B L)$ which require the classroom and lecturer, TBL require the student to embark on the non-face to face reading at home of the topic in the form of individual and group assessment learning experience thus enrich more of the students' knowledge of the course rather than focusing to the information from a single lecturer only (Chen et al., 2018). This allow the students especially in the fast pace and hectic study environment such medical to access the knowledge anywhere and at any time thus creating the learning without the classroom barricade as the lecture-based learning had done for centuries.

Further, TBL applies a pre-arranged small group learning session that can later be extended to the larger group of students (Rajalingam et al., 2018). This small group learning session is expected to enrich the student's aptitude of searching knowledge using available resources (online reading, library or anatomy museum etc.) thus extend the horizon of medical terminology source of information. The approach is believed to be able to reduce the students face to face time with the lecturer and increase the non-face to face time between the students and instructors (Hassan et al., 2018). Next, the TBL is believed to be able to deliver a long-life learning experience among the students as well as developing the self-directed learning attitude. This is done through a selfempowerment approach being given to the students that require them to prepare in advance of the technicalities as well as other views of the topic they are required to study before the traditional class begins (Ramnanan \& Pound, 2017). With the students are tasked to search for the knowledge beyond the boundary of the traditional textbook and constricted notes given by the lecturer or professors, gone are the days where lecture-based learning is being used as the sole teaching method in the teaching pedagogy. In addition to that, it must be noted that the TBL offers various positive outcomes to the students learning experience. Better preparation of not wanting to disappoint the team members expectation, competitiveness, immediate feedback and argument of ideas are illustrated as the advantages of having TBL method in the learning session although the hybrid of problem-based learning and team-based learning is also preferred (Burgess, Roberts, Ayton, \& Mellis, 2018).

Moreover, in a study of Soleimanpour et al. (2018) among the medical residents' knowledge about mild induced hypothermia after cardiac arrest had found that there are no significant difference of the knowledge the respondents acquired in both lecture based learning and e-learning methods although the differences were noted positively in pre and post-test of the experiment. In contrast of a study about problem-based learning (PBL) versus team based learning (TBL) among Year 1 medical 
students, had found that more students prefer to continue with the TBL style of teaching methodology as it offers better grasp of self-learning skills and critical thinking skills than the earlier concept (Burgess et al., 2018). Other than that, the students teamwork skills and lifelong learning skills were recorded to improve as the students embark in the TBL learning methodology (Remington et al., 2017).

Nevertheless, although the TBL method has been implemented in many medical teaching facilities and centre, little is known of the TBL approach is being practiced in UiTM as part of the learning intervention especially in the medical and health terminology for health administration students. The objective of this study was to assess pre-perception and post-perception of TBL on learning medical and terminology course among undergraduate students of Health Administration program in UiTM Selangor, Puncak Alam Campus.

\section{Method}

Design and participants. A census sample was employed based on the class enrolment of the bachelor degree program. A pre-and post-study was conducted to measure student's perception towards TBL session and facilitator's knowledge on TBL. This was achieved by participation of 33 undergraduates who are in the second-year of Health Administration course (BM235) from UiTM Selangor, Puncak Alam Campus and a total 31 lecturers from the Department of International Business and Management. TBL was applied in a 4-credit Medical and Health Terminology course which consists of two components including 1) anatomy and physiology of the human body systems and 2) description of the medical terminologies. TBL was conducted in two phases; 1 ) pre-class preparation and 2) readiness assurance test (Ismail et al. 2016).

Pre-class preparation. The students were informed of the topic to be covered in the TBL one week before the session. Learning objectives for each session were clearly specified by the facilitators, and the students were asked to watch online modules, images and video on Youtube ${ }^{\mathrm{TM}}$ that are relevant to the topics to enhance their understanding about the topic. Then, they were asked to develop a mind map and submit them using their i-Learn account (UiTM e-learning platform). Students were expected to review and be prepared to utilize the information during the TBL in class session.

Readiness assurance test. During this phase, students were asked to complete two tests; Individual Readiness Test (IRT) and Group Readiness Test (GRT). The tests consist of two sections; in section A, students were asked to build and translate medical terms and in section B students were asked to explain the anatomical structure of the body systems. Thirty minutes (30) of time was allocated for the completion of the tests at the end of which the students were asked to submit their answer sheets.

Data collection and statistical analyses. The data was collected in July 2018 using 27-items selfadministered questionnaire (Vasan, DeFouw, \& Compton, 2009). Perception of TBL was measured by 12 items, teamwork was evaluated by 8 items and 7 items were measured knowledge of facilitator on overall TBL. All items used a five-point Likert scale where 1=strongly disagree, 2=disagree, $3=$ uncertain, 4=agree and 5=strongly agree. Then, the score was categorized into "positive" and 
"negative" response. Mean score was used as cut off point for classification, in which score higher than mean is considered "positive" evaluation and score lower than mean is considered "negative" evaluation. The questionnaire was administered twice, before and after TBL session. Descriptive analysis reports student's evaluation on the TBL and teamwork; and their expectation on the final grade as well as mean score of each item in the questionnaire. Meanwhile, paired-t test (dependent t-test) compared mean score before and after TBL implementation.

\section{Findings and Discussion}

A total of 37 students registered for the medical and health terminology subject, however, only 33 students participated in the TBL session. Of 33 students, $16(48.5 \%)$ of participants had science background and $17(51.5 \%)$ had no background in science. More than half of the students evaluated positive feedback towards TBL (60.6\%) and teamwork (54.5\%). Table 1 shows the perception of TBL and teamwork among the students.

Table 1. Perception on TBL and team work

\begin{tabular}{lcc}
\hline Variables & \multicolumn{2}{c}{ Perception (\% of student) } \\
\hline & Positive & Negative \\
TBL & $60.6 \%$ & $39.4 \%$ \\
Team work & $54.5 \%$ & $45.5 \%$ \\
\hline
\end{tabular}

In terms of teaching staff, there were 31 lecturers who had agreed to provide their response on the knowledge of TBL teaching method at the faculty. Majority of the respondents were female $(n=25$, $81 \%)$ and married $(n=26,84 \%)$. More than $40 \%(n=14)$ of respondents had more than 10 years of teaching experience and $70 \%(n=22)$ were at age range $30-40$ years old. Nearly $55 \%(n=17)$ of respondents were received between 16 to 18 hours of teaching load per semester. Overall, $48 \%$ $(n=15)$ of respondents were considered themselves having good knowledge of TBL teaching method and $52 \%(n=16)$ had poor/less knowledge of this teaching method.

There was statistically significant improvement in mean perception of overall TBL and teamwork before and after TBL implementation (Table 1). Table 2 describes the mean and standard deviation of data. It was reported that the item "I learned useful additional information during the TBL sessions" considered as the highest mean score (pre-M=3.51, $S D=0.97$, post $-M=4.39, S D=0.50$ ). On the other hand, the lowest mean score was obtained by the item "I contributed meaningfully to the TBL discussions" (pre - $M=3.00, S D=0.83$; post $-M=4.27, S D=0.57$ ). Figure 1 and Figure 2 show expectations and the final grade achieved by students. 
INTERNATIONAL JOURNAL OF ACADEMIC RESEARCH IN BUSINESS AND SOCIAL SCIENCES Vol. 9, No. 13, Special Issue: Revolutionizing Education: Challenges, Innovation, Collaboration., 2019, E-ISSN: 2222-6990 @ 2019 HRMARS

Table 2. Mean score according to item

\begin{tabular}{|c|c|c|}
\hline \multirow{2}{*}{$\begin{array}{l}\text { Item } \\
\text { Perception on TBL }\end{array}$} & \multicolumn{2}{|c|}{ Mean(SD) } \\
\hline & $\begin{array}{l}\text { Pre- } \\
\text { perception }\end{array}$ & $\begin{array}{l}\text { Post- } \\
\text { perception }\end{array}$ \\
\hline $\begin{array}{l}\text { TBL helped me increase my understanding of the course } \\
\text { material }\end{array}$ & $3.48(0.87)$ & $4.39(0.50)$ \\
\hline I have completed $100 \%$ of the required reading & $3.21(0.78)$ & $4.10(0.58)$ \\
\hline Learning issues helped me to focus on core information & $3.51(0.83)$ & $4.12(0.33)$ \\
\hline $\begin{array}{l}\text { Individual readiness assurance tests (IRAT) were useful } \\
\text { learning activities }\end{array}$ & $3.33(0.85)$ & $4.12(0.60)$ \\
\hline I generally felt prepared for the IRAT & $3.07(0.79)$ & $4.18(0.53)$ \\
\hline $\begin{array}{l}\text { Discussions of the TBL learning issues were useful learning } \\
\text { activities. }\end{array}$ & $3.27(0.88)$ & $4.42(0.56)$ \\
\hline I learn better from lecture presentations than small group & $3.48(0.94)$ & $4.12(0.65)$ \\
\hline $\begin{array}{l}\text { I learned useful additional information during the TBL } \\
\text { sessions }\end{array}$ & $3.51(0.97)$ & $4.39(0.50)$ \\
\hline TBL helped me prepare for course examinations & $3.27(0.98)$ & $4.21(0.55)$ \\
\hline $\begin{array}{l}\text { The GRAT (group) discussions allowed me to correct my } \\
\text { mistakes and improve understanding of } \\
\text { the concepts. }\end{array}$ & $3.30(0.81)$ & $4.30(0.47)$ \\
\hline I paid attention most of the time during the TBL sessions & $3.15(0.83)$ & $4.24(0.44)$ \\
\hline $\begin{array}{l}\text { The TBL format was helpful in developing my information } \\
\text { synthesizing skills }\end{array}$ & $3.21(0.74)$ & $4.39(0.56)$ \\
\hline \multicolumn{3}{|l|}{ Perception on team work } \\
\hline $\begin{array}{l}\text { Solving problems in a group is an effective way to learn } \\
\text { anatomy. }\end{array}$ & $3.45(0.94)$ & $4.36(0.55)$ \\
\hline I have a positive attitude about working with my peers & $3.30(0.95)$ & $4.30(0.59)$ \\
\hline $\begin{array}{l}\text { The ability to collaborate with my peers is necessary if I am } \\
\text { to be successful as a student }\end{array}$ & $3.48(0.94)$ & $4.21(0.55)$ \\
\hline $\begin{array}{l}\text { Solving problems in a group is an effective way to practice } \\
\text { what I have learned. }\end{array}$ & $3.52(0.91)$ & $4.39(0.61)$ \\
\hline My team worked well together & $3.36(0.90)$ & $4.42(0.56)$ \\
\hline I contributed meaningfully to the TBL discussions & $3.00(0.83)$ & $4.27(0.57)$ \\
\hline Most students were attentive during TBL sessions & $3.00(0.87)$ & $4.24(0.44)$ \\
\hline $\begin{array}{l}\text { There was mutual respect for other teammates' viewpoints } \\
\text { during }\end{array}$ & $3.36(0.90)$ & $4.27(0.57)$ \\
\hline
\end{tabular}


A paired-samples t-test was conducted to evaluate the perception of students on TBL and teamwork before and after TBL session. Data results were shown in Table 3. There was a statistically significant in TBL and teamwork scores at pre-study $(M=3.32, S D=0.64)(M=3.32, S D=0.75)$ respectively to post study $(\mathrm{M}=4.25, \mathrm{SD}=0.35)(\mathrm{M}=4.31, \mathrm{SD}=0.40)$ respectively at $\mathrm{P}<0.01$.

Table 3. Perceptions before and after TBL session

\begin{tabular}{lllccccc}
\hline & & \multirow{2}{*}{ Mean (SD) } & \multicolumn{2}{c}{$95 \%$ confidence interval } & & \multirow{2}{*}{$\mathrm{P}$} & \\
\cline { 4 - 5 } & & & Lower & Upper & & & \\
\hline \multirow{2}{*}{ Pre-Post TBL } & Perceptions of TBL & $-.93(0.65)$ & -1.25 & -.739 & -7.99 & $<0.01$ \\
& Perceptions of team & $-.99(0.71)$ & -1.16 & -.7 .02 & -8.26 & $<0.01$ \\
& work & & & & & & \\
\hline
\end{tabular}

*Paired t-test, significant at $\mathrm{P}<0.05$

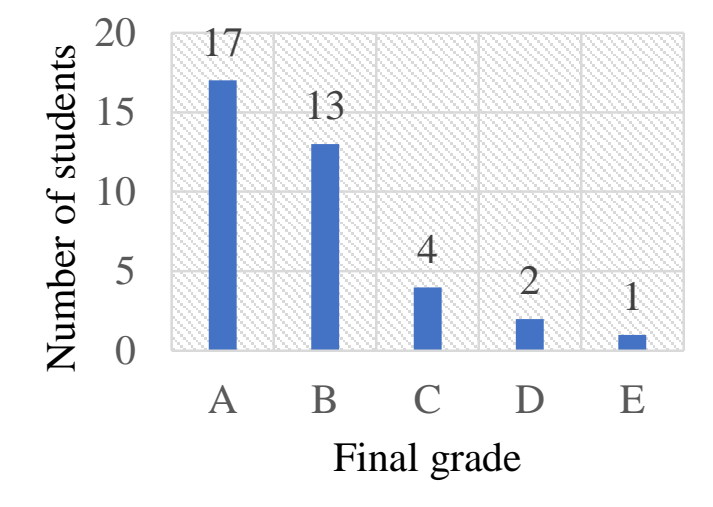

Fig 2. Student's expectation on the final grade

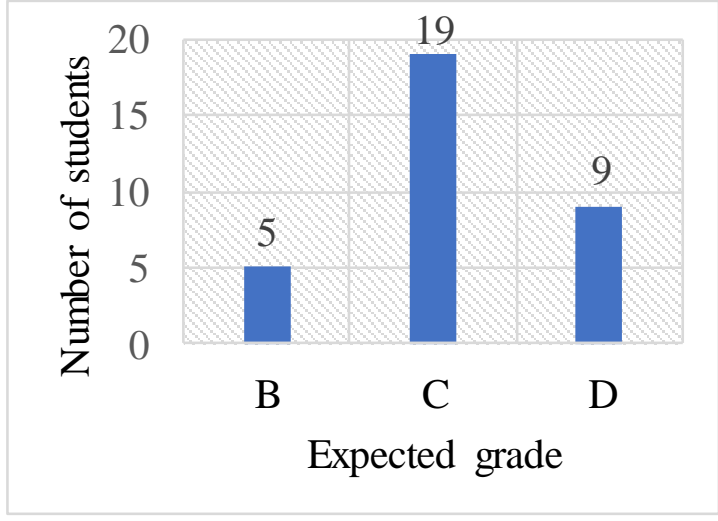

Fig.1 Student's final grade

\section{Discussion}

This study was instigated to measure pre-perception and post-perception of TBL and teamwork which was applied on medical and health terminology course of the Health Administration program. The purpose for this approach is to enhance the implementation of TBL in the UiTM Selangor, Puncak Alam campus, particularly in the Department of International Business and Management. Result indicates that TBL significantly increased student's understanding about the course material and improved their team learning. This might be because they felt solving problems in a group is an effective way to practice what they have learned thus providing them with an opportunity to better prepare for final exam. This is especially relevant as the majority of the students enrolled in this program had no science background. Hence, TBL might enable them to work independently and as a team in learning the subject. As evident by Haidet et al. (2004), learning in team offers more active participation that fosters knowledge building than traditional lectures. Furthermore, active learning sessions would help students to better comprehend key concepts and to prioritize information, thus enables them to effectively answer the questions. Also, by giving students practice questions prior to the exam would reduce test anxiety (Favero, 2011). Active learning such as TBL has been used extensively in healthcare education. In this discipline, students are required to possess critical 
thinking and learn skills necessary for evidence-based practice rather than passively listening to lectures (Boctor et al. 2013, Zgheib, Simaan, \& Sabra, 2011). A study evaluated effectiveness of TBL among students in surgery clerkship has gained positive feedbacks. They specified that TBL were helpful and promotes interactive learning (Kaminski et al., 2018). Meanwhile, Miller et (al. 2017) found a positive attitudes towards TBL in terms of learning effectiveness among pharmacy students. Similarly, more than half of medical students enrolled in the College of Medicine in United Arab Emirates agreed that TBL increased their enablement of course content and improved interpersonal and communication skills (Alwahab et al., 2018).

To enhance the outcome of TBL in this setting, team exams could also be introduced for the subject. Although failure rate for this subject has decreased, but there are proportion of students who are still fail in every semester. It is understandable that team exams provide better chance for the students to critically analyze questions within a setting that fosters peer discussion, explanation and debate. Additionally, team exams assist students to feel prepared and more confident by providing them with the opportunity to identify class content that is challenging to them, recognize gaps in their knowledge, and strengthen their skills through discussion and debate with their team. This is because during final examination, students may find it difficult to answer complex and in-depth questions correctly without having a chance to discuss and defend their rational and receive a counter argument to their answer choice (Khansari \& Coyne, 2018).

Apart from that, changes in the current classification of students would provide better TBL results. Currently, students in this program are grouped based on their previous education background. To achieve maximum benefit of TBL, these students should be combined in one group so then students who have basic science could help their friends who have no background in science. However, replacement to the normal practice of teaching is not easy as it requires full cooperation from faculty administration and lecturers. As supported by Thompson et al. (2007) who has demonstrated lack of support by the faculty and negative attitude hinders TBL implementation in many settings. This study subjected to limitations such as the TBL was conducted in only one session and involves only medical and health terminology course.

\section{Conclusion}

Overall, the implementation of TBL for medical teaching and health terminology course has received a good feedback from the students. The approach should be carried out on various courses and program. Knowledge among lecturers was considered fairly rated as good and poor relating to TBL teaching method.

\section{Acknowledgement}

This study was funded by the Academic and Research Assimilation Scheme (ARAS) Grant (Code Project: 003/2016). 


\section{References}

Alwahab, A., Abdulqader, S., Nugud, A., Nugud, S., Cyprian, F., Shaikh, A. A., \& Anwar, K. (2018). Teambased learning in an undergraduate pathology curriculum and its effects on student performance. Journal of Taibah University Medical Sciences, 13(5), 496-501.

Burgess, A., Roberts, C., Ayton, T., \& Mellis, C. (2018). Implementation of modified team-based learning within a problem based learning medical curriculum: a focus group study. BMC Medical Education, 18(74), 1-7. doi:https://doi.org/10.1186/s12909-018-1172-8

Chen, M., Ni, C., Wang, M., Liu, L., Ji, X., Chu, H., . . . Wang, X. (2018). Meta-analysis on the effectiveness of team-based learning on medical education in China. BMC Medical Education, 18(77), 1-11. doi:https://doi.org/10.1186/s12909-018-1179-1

Favero, T. G. (2011). Active review sessions can advance student learning. Advances in Physiology Education, 35(3), 247-248.

Haidet, P., Morgan, R. O., O’Malley, K., Moran, B. J., \& Richards, B. F. (2004). A Controlled Trial of Active Versus Passive Learning Strategies in a Large Group Setting. Advances in Health Sciences Education, 9(1), 15-27.

Hassan, S., Ibrahim, M. S., \& Hassan, N. G. (2018). The structural framework, implementation strategies and students' perception of team based learning in undergraduate medical education of a Medical School in Malaysia. Education in Medicine Journal, 10(1), 55-68. doi:10.21315/eimj2018.10.1.7

Kaminski, A. D., Babbitt, K. M., McCarthy, M. C., Markert, R. J., Roelle, M. P., \& Parikh, P. P. (2018). Team-Based Learning in the Surgery Clerkship: Impact on Student Examination Scores, Evaluations, and Perceptions. Journal of Surgical Education, 30-35.

Khansari, P. S., \& Coyne, L. (2018). An innovative addition to team-based-learning pedagogy to enhance teaching and learning: Students' perceptions of team exams. Currents in Pharmacy Teaching and Learning, 10(1), 90-95.

Miller, D. M., Khalil, K., Iskaros, O., \& Amburgh, V. J. A. (2017). Professional and pre-professional pharmacy students' perceptions of team based learning (TBL) at a private research-intensive university. Currents in Pharmacy Teaching and Learning, 9(4), 666-670.

Rajalingam, P., Rotgans, J. I., Zary, N., Ferenczi, M. A., Gagnon, P., \& Low-Beer, N. (2018). Implementation of team-based learning on a large scale: Three factors to keep in mind. Medical Teacher, 40(6), 582-588. doi:https://.doi.org/10.1080/0142159X.2018.1451630

Ramnanan, C. J., \& Pound, L. D. (2017). Advances in medical education and practice: student perceptions of the flipped classroom. Advances in Medical Education and Practice, 8, 63-73.

Remington, T. L., Bleske, B. E., Bartholomew, T., Dorsch, M. P., Guthrie, S. K., Klein, K. C., ... Wells, T. D. (2017). Qualitative analysis of student perceptions comparing team-based learning and traditional lecture in a pharmacotherapeutics course. Americal Journal of Pharmaceutical Education, 81(3), 1-9.

Soleimanpour, M., Rahmani, F., Golzari, M. N., Ala, A., Reza, H., Bagi, M., . . Soleimanpour, H. (2018). Comparison of electronic learning versus lecture-based learning in improving emergency medicine residents' knowledge about mild induced hypothermia after cardiac arrest. Anesth Pain Med, 7(4), e57821. doi:10.5812/aapm.57821 
Thompson, B. M., Schneider, V. F., Haidet, P., Levine, R. E., McMahon, K. K., Perkowski, L. C., \& Richards, B. F. (2007). Team-based learning at ten medical schools: two years later. Medical Education, 41(3), 250-257.

Vasan, N. S., DeFouw, D. O., \& Compton, S. (2009). A survey of student perceptions of team-based learning in anatomy curriculum: Favorable views unrelated to grades. Anatomical Sciences Education, 2(4), 150-155.

Zgheib, N. K., Simaan, J. A., \& Sabra, R. (2011). Using Team-based Learning to Teach Clinical Pharmacology in Medical School: Student Satisfaction and Improved Performance. The Journal of Clinical Pharmacology, 51(7), 1101-1111. 